\title{
The Impact of Diabetes in Children on Dental Caries
}

\author{
Karimi * \\ Internal Auditor \& Documentations at Apple Dental Clinic, Iran
}

Received: May 15, 2018; Published: May 30, 2018

*Corresponding author: Karimi, Internal Auditor \& Documentations at Apple Dental Clinic, Iran

\section{Short Communication}

Diabetes is a metabolic disorder characterized by abnormal glucose uptake. It can have deleterious effects on many organs of the body, including the oral cavity. Diabetes has an important relation to oral health and vice versa. Diabetes increases the risk of gum disease, tooth decay, tooth loss, dry mouth, and various types of oral infections. Therefore, oral and dental diseases are one of the complications of diabetes. As you know, diabetes is a disease that has many long-term effects. One of these complications is oral and dental problems. Because children with diabetes are at greater risk for infection, they are more prone to many oral and dental problems. These problems include a wide range of fungal and oral infections, to dry mouth, and the weakness of the healing process after dental treatments. When you think about the complications of diabetes, you may not have oral and dental health at the top of the list, but the frequency of dental caries is one of the symptoms that affect a person with diabetes [1-6].

The reason for this is that diabetes reduces patient's resistance to infection. Bacteria, viruses and fungi live naturally in the mouth. When diabetes goes out of control, increasing the amount of glucose (salivary glycogen) helps bacteria. The most common oral health problems associated with diabetes are dental caries, gum disease, salivary gland dysfunction, fungal infection, and delayed healing. Periodontal disease is one of the problems which are often seen among diabetic patients. The relationship between diabetes and dental caries has already been studied, but there is no meaningful relationship. While the relationship between diabetes and periodontal disease has already been documented, it is not possible to explicitly link the relationship between diabetes and dental caries. In addition, people with diabetes are more susceptible to have infection, including dental abscesses which are caused by advanced dental caries.

Studies have shown that patients with diabetes are more susceptible to periodontal and salivary disorders, which can increase the risk of new and recurrent caries. Periodontal disease can cause jaw bone loss and gingival recession, which inevitably might expose more dental surfaces to decay. People with diabetes can also have low salivary secretion and may suffer from salivary function. In chil dren, adolescents and adults who are hyperglycemic, we will see a decrease in salivation and concentration of saliva. In addition to calcium and phosphates that help remineralization of the enamel, the saliva also contains molecules that can directly attack the bacteria. Lack of excessive saliva may lead to a decrease in buffering activity, which can speeds up reduction of the amount of saliva leads to reducing a resistance to the bacteria. In addition, high levels of glucose in saliva can increase the amount of carbohydrates that can be fermented by using oral bacteria, resulting in the production of acidic side effects that can cause tooth decay. The abundance of glucose in saliva can also promote the growth of reducing bacteria and the frequency and duration of acid release [7-10].

The oral cavity is constantly exposed to salivation and secretion. Diabetes mellitus can cause changes in the function of salivary glands, which may help reduce blood flow and alter the composition of the saliva. In some studies, the results showed that patients with diabetes mellitus are at high risk for tooth decay. From the point of view of oral consequences, the physical and biological risk factors for caries in the enamel or root surfaces of the tooth include the inadequate composition and the flow of the salivary glands, the emergence of sufficient fluoride, gingival loss, immunological components, a large number of reducing bacteria ,need for special care and the genetic factors. Caries are related to the lifestyle of a person and these behavioral factors are clearly under the control of the individual. These factors include poor oral health and poor eating habits, such as frequent use of refined carbohydrates, and frequent use of sugar-containing oral medications. Although some studies have advocated the impact of childhood diabetes on dental caries, some others have controversy about this issue. In fact, they believe the impact of diabetes on teeth decay is debatable.

\section{References}

1. Dental caries (2003) the disease and its clinical management. Copenhagen, Denmark: Blackwell Monksgaard.

2. Selwitz RH, Ismail AI, Pitts NB (2007) Dental caries. Lancet 369(9555): 51-59.

3. Featherstone JD, Adair SM, Anderson MH, Berkowitz RJ, Bird WF, et al. (2003) Caries management by risk assessment: consensus statement, April 2002. J Calif Dent Assoc 31(3): 257-269. 
4. Caulfield PW, Griffen AL (2000) Dental caries. An infectious and transmissible disease. Pediatr Clin North Am 47(5): 1001-1019.

5. Featherstone JD (2004) The continuum of dental caries--evidence for a dynamic disease process. J Dent Res 83 Spec No C: C39-C42.

6. Krol DM (2003) Dental caries, oral health, and pediatricians. Curr Probl Pediatr Adolesc Health Care 33(8): 253-270.

7. Grossi SG (2001) Treatment of periodontal disease and control of diabetes: an assessment of the evidence and need for future research. Ann Periodontol 6(1): 138-145.



Submission Link: https://biomedres.us/submit-manuscript.php
8. Karjalainen KM, Knuuttila ML, Kaar ML (1996) Salivary factors in children and adolescents with insulin-dependent diabetes mellitus. Pediatr Dent 18(4): 306-311.

9. Syrjala AM, Niskanen MC, Ylostalo P, Knuuttila ML (2003) Metabolic control as a modifier of the association between salivary factors and dental caries among diabetic patients. Caries Res 37(2): 142-147.

10. Hintao J, Teanpaisan R, Chongsuvivatwong V, Dahlen G, Rattarasarn C (2007) Root surface and coronal caries in adults with type 2 diabetes mellitus. Community Dent Oral Epidemiol 35(4): 302-309.

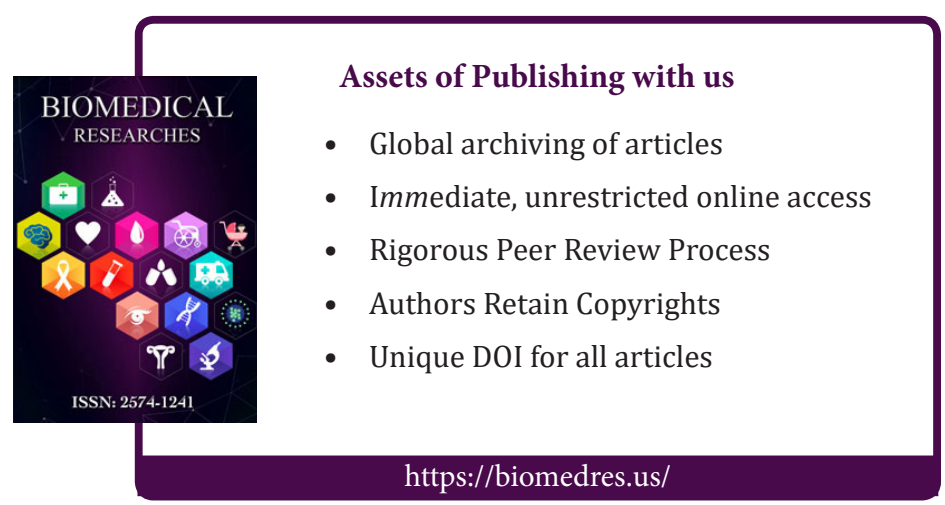

